\title{
Multilinguales
}

\section{Contacts de langues et/ou de cultures dans les contes populaires écrits en langue française}

Contacts of languages and / or cultures in popular tales written in French language

Tahar Hamadache

\section{(2) OpenEdition}

\section{Journals}

Édition électronique

URL : https://journals.openedition.org/multilinguales/4517

DOI : 10.4000 /multilinguales. 4517

ISSN : 2335-1853

Éditeur

Université Abderrahmane Mira - Bejaia

Référence électronique

Tahar Hamadache, « Contacts de langues et/ou de cultures dans les contes populaires écrits en langue française », Multilinguales [En ligne], 12 | 2020, mis en ligne le 14 février 2020, consulté le 30 juin 2021. URL : http://journals.openedition.org/multilinguales/4517 ; DOI : https://doi.org/10.4000/ multilinguales. 4517

Ce document a été généré automatiquement le 30 juin 2021.

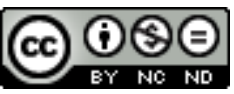

Multilinguales est mise à disposition selon les termes de la Licence Creative Commons Attribution Pas d'Utilisation Commerciale - Pas de Modification 4.0 International 


\title{
Contacts de langues et/ou de cultures dans les contes populaires écrits en langue française
}

\author{
Contacts of languages and / or cultures in popular tales written in French \\ language
}

Tahar Hamadache

1 Les contes populaires constituent, depuis toujours, un terrain de rencontres, de fusion et de tensions interculturelles et transculturelles multiples. Dès l'empire romain, Apulée de Madaure a reposé son œuvre romanesque L'Âne d'or sur les contes populaires pour affirmer son indépendance d'esprit face aux thuriféraires de l'Empire comme pour informer de la capacité de sa culture à être une alter-égo de la culture romaine, y compris en langue latine. En Europe, ils ont très tôt servi de base de lancement de la littérature humaniste (Straparole, etc.) puis, notamment en France, consécutivement à la bataille des "Anciens" et des «Modernes", de la littérature moderne, sous l'impulsion de Charles Perrault et, enfin, à divers genres littéraires ultérieurs dont la fable, le conte-nouvelle et la nouvelle.

2 Ils ont par ailleurs servi de viviers par lesquels se sont affermies les cultures nationales des Etats-Nations modernes, avant de venir en renfort à l'identité européenne en construction. Des travaux ethnologiques à ceux des folkloristes et des anthropologues, les recueils de contes ont servi diverses tendances idéologiques allant de celles dominatrices et colonialistes, à celles de la recherche de cultures exotiques, à celles universalistes. Des conventions les ont intégrés dans le patrimoine immatériel, de l'humanité pour l'Unesco, national pour des pays dont l'Algérie.

Ils sont valorisés lorsqu'ils participent d'idéologies et de projets puissants, mais considérés comme étant subversifs et fustigés en tant que «menteries ", « littérature mineure », « historiettes » lorsqu'ils émanent de volontés isolées ou périphériques.

Quel que soient l'époque et l'intention auctoriale et éditoriale première, et si la langue dans laquelle les contes populaires sont écrits est en cause dans les représentations qui 
entoure leur édition, c'est davantage le fonds culturel, les valeurs et l'identité culturelle desquels ils participent qui sont le plus étudiées et retenu l'attention.

La spécificité du genre n'est pourtant pas sans susciter des questions quant aux contacts des langues qu'il charrie du fait qu'ils sont recueillis à partir de divers terroirs oraux de par le monde pour être publiés en d'autres langues. C'est le cas précisément de la foisonnante édition de contes en langue française, objet du présent article.

Dans quelle mesure peut-on distinguer différentes situations de contact de langues en étudiant un corpus de contes? Si oui, ces situations de contact de langues caractérisent-elles les contes en tant que genre de discours littéraire et se distinguentelles de celles étudiées dans l'écriture littéraire bilingue? Enfin, à quelles réflexions de teneur ou de portée didactique ces situations invitent lorsque l'enseignement/ apprentissage du FLE porte sur le genre « conte »?

Nous pensons que les contacts de langue que l'on peut rencontrer dans les contes populaires écrits en français relèvent de divers types: ils peuvent relever du style d'auteur, de contraintes de traduction ou visant des effets (pragmatiques) à la réception, et qu'ils peuvent varier selon la formation de l'auteur, l'origine de tel ou tel conte source, et l'intention éditoriale.

\section{Cadre théorique}

5 Les contacts de langue en littérature sont des procédés d'écriture. Ils s'analysent en termes d'énonciation diégétique, de composition textuelle, de personnages. Dans les contes populaires publiés en français, ils constituent en outre des «realea», non seulement ancrés à la réalité ordinaire de la culture d'origine et/ou de l'auteur, mais témoignant aussi de leur inscription dans la littérature orale et l'imaginaire folkloriques duquel ils ont été recueillis. Ils ne sortent du texte qu'à la réception pour se confronter aux représentations du lecteur, à son bi/plurilinguisme propre ou au contexte bi/plurilingue et interculturel de la classe ou de l'environnement sociolinguistique. Nous ne prétendrons pas aborder dans ce travail toutes les facettes de contacts de langues, de cultures, de discours.

6 A partir de la jonction entre sociolinguistique et analyse du discours (Boutet et Maingueneau, 2005), nous nous limiterons à puiser des concepts de la sociolinguistique étudiés sur corpus littéraire (Abbas-Kara et Kebbas, 2013), précisément du genre du conte populaire (Kossogorova, 2012), tout en référant davantage aux travaux sur le bilinguisme littéraire (Clement, 2007). Notre objectif est de parvenir à des propositions (socio)didactiques qui, tout en s'inspirant des travaux portant sur l'enseignement bi/ plurilingue, pourraient s'accorder davantage avec l'enseignement/apprentissage du genre conte dans un cadre sociodidactique.

\section{Bilinguisme et diglossie sociolinguistique}

7 L'émergence au début du XXe S. de narrateurs/» parleurs "populaires" » à l'encontre du «narrateur "lettré"» ouvre de ce fait l'œuvre littéraire à l'observation sociolinguistique dès lors que «la langue unique étant une visée politique, non un fait historique, tout choix dans la variation inhérente à la langue est assimilable à une "prise de position" dans le champ littéraire » (Meizoz, 2005). Il est à remarquer que 
c'est de cette époque que les contes populaires, y compris du patrimoine français, ont entamé en France un regain d'intérêt, désormais pris en charge par les folkloristes et non plus seulement par les ethnologues coloniaux.

Les enjeux liés aux contacts des langues dans les contes populaires publiés en langue française diffèrent suivant qu'ils relèvent de la responsabilité éditoriale ou de celle auctoriale. En effet, vus en tant que genre, ces contes mettent en valeur la capacité de la langue française à traduire les patrimoines des plus diverses cultures et participent de leur sauvegarde, tout en les mettant à la disposition de la francophonie littéraire et au service de l'illustration de la langue française. Les enjeux y liés sont alors à rechercher aux niveaux glottopolitique et du marché des langues internationales dominantes. Lorsqu'ils tiennent de la responsabilité auctoriale, les contacts de langue servent d'abord à garantir l'authenticité culturelle des contes-sources et inviter de ce fait à des lectures transtextuelles, y compris documentaires. Suivant les auteurs et leurs distances par rapport aux cultures-sources, les enjeux des procédés bilingues peuvent venir en renfort de ceux courus par l'instance éditoriale et/ou présenter des similarités avec ceux que l'on peut déceler dans l'écriture romanesque.

Clément (2007) a développé un appareil conceptuel pour analyser les aspects du bi/ plurilinguisme littéraire présents dans une œuvre romanesque susceptibles de servir à mobiliser les concepts de la sociolinguistique de façon plus en phase avec les outils de l'analyse du discours littéraire ainsi qu'avec la narratologie et donc plus adéquate avec la nature littéraire, fictionnelle et imaginaire des œuvres étudiées. L'auteure distingue le "plurilinguisme littéraire ", le "plurilinguisme diégétique » et le "bilinguisme culturel» présents dans une œuvre. Le premier concerne, selon elle, l'auteur ou la personne de l'écrivain. Le deuxième regroupe, quant à lui, en les distinguant, le bilinguisme des instances énonciatives diégétiques: narrateur, auteur et lecteur diégétiques, ainsi que de toute manifestation de «bilinguisme scriptural ». Le troisième est enfin subdivisé en «bilinguisme spacioculturel » ou " géoculturel » d'une part, et «bilinguisme socioculturel » d'autre part. Ce concept est, suivant l'auteure, lié à celui de " polylinguisme » bakhtinien. Tout en étant inscrit dans la diégèse, le «bilinguisme culturel» rend compte, selon l'auteure, des contacts de langues entre espaces fictionnels linguistiques, langagiers et discursifs présents dans l'œuvre, ainsi que de ceux opérant entre catégories et postures sociolinguistiques des personnages fictifs, ces " êtres de papier». Le bilinguisme culturel charrie avec lui les différences existant entre univers culturels différents. On peut au passage postuler que les éléments entrant dans la catégorie «bilinguisme culturel » sont propres à autoriser une confrontation hypothétique entre « horizon d'attente » et réception.

En travaillant sur les seuls contes russes, Kossogorova (2012) répartit quant à elle les éléments pertinents $\mathrm{du}$ point de vue de la sociolinguistique en trois catégories lexicales : historique, folklorique et phraséologique. A notre sens, les deux premières catégories caractérisent le genre de discours littéraire qu'est le conte, tout en s'adaptant aux cultures locales à partir desquelles ils sont recueillis. Celle des figements de langue met en contact les phraséologies des langues-source respectives et celle du français. L'intérêt de scruter le contact des langues à ces trois niveaux se justifie du fait qu'ils éclairent davantage le «bilinguisme diégétique» et le «bilinguisme culturel » retenus par Clément (2007) tout en permettant d'avoir accès sur les contacts interculturels (Ammouden et Hamadache, 2018; Hamadache et 
Ammouden, 2019) ainsi que sur les contacts entre l'oralité des versions hétéroglottes d'origine et l'édition francophone (Hamadache, 2018 ; Hamadache et Ammouden, 2019). Etudiant les modalités d'insertion d'éléments de «la langue des origines» de trois écrivains algériens, Abbas-Kara et Kebbas (2013) y ont recensé trois procédés de l'écriture bilingue : le xénisme, l'emprunt et le calque, non sans évoquer le discours épilinguistique assumé par les personnages romanesques.

\section{Analyse du corpus}

\subsection{Faits de bilinguisme littéraire}

11 Etant donné l'origine populaire, dans beaucoup de cas éloignée de la langue française, des contes de tous pays publiés en français, les marques de contacts de langues et/ou de cultures, explicites ou implicites, sont prévisibles. Leur présence est fréquemment suggérée dès la couverture de l'ouvrage par les titres qui réfèrent à l'origine des contes, les intitulés des collections et autres informations y figurant. Leur absence même peut s'avérer significative quant à la position de l'auteur par rapport à la langue et à la culture source.

Le discours épilinguistique de l'auteur est aussi à considérer sous ce rapport de bilinguisme littéraire car assez souvent présent dans les préfaces, introductions et autres éléments péritextuels. Vu l'existence de variantes de contes produites par différents auteurs, parfois recueillis dans un même terreau géoculturel, aussi bien le discours épilinguistiques que les choix d'insertions hétérolingues dans le texte français peuvent être mis en regard les uns des autres.

\subsection{Faits de bilinguisme diégétique}

\section{a. Xénismes}

Les xénismes sont habituellement définis comme étant tous les termes étrangers à la langue française, dont les noms propres. Sauf lorsqu'ils sont accompagnés d'explications, ce qui dénote textuellement leur xénité, lorsqu'il s'agit de noms communs, nous les rangeons ici avec les emprunts.

Les noms propres peuvent aussi relever du monde historique propre à la culture source des contes, tout en étant empruntés par le monde imaginaire des contes tels que des noms de lieux réellement existants :

(1) $[11]^{1}$ Lannion

(2)[10] Mekke

ou des noms de personnes réellement usités dans telle ou telle communauté :

(3)[11] Loeiz

(4) [12] Léopold

(5) [17] Bourtoumiu

Ils peuvent aussi être réservés au monde folklorique caractéristique d'un seul conte

(6) [9] Hamed ben Çeggad

(7) [10] Medrabalef

(8) [19] Terracamina

ou apparaitre dans plusieurs contes d'un même terroir :

(9) [1] Tseriel 
(10) [5] l'awarzeniou .

(11) [16] Korrigan

Noms communs ou noms propres de personnages sont parfois expliqués par l'un des nombreux procédés (Cheriguen, 2002): traduction mise en parenthèse ('achouch), extension explicative (de la mosquée), explication mise en apposition, etc.

(12) [7] une baraque ('achouch)

(13) [2] le cheikh (de la mosquée)

(14) [2] Settoute, la vieille sorcière

13 De ce qui précède, on peut voir que les contacts de xénismes font apparaitre diverses dimensions du conte populaire publié en français, langue d'asile de la littérature francophone. En effet, il peut être considéré en tant qu'œuvre singulière aussi bien qu'en tant que genre littéraire qui se distingue par une position à la charnière entre monde historique et monde imaginaire, entre terroir local frisant la légende et domaine interculturel méritant la définition de patrimoine de l'humanité.

\section{b. Emprunts}

Dubois et Al. (2012) écrivent à propos de l'emprunt : «L'emprunt est le phénomène linguistique le plus important dans tous les contacts de langue ",

ajoutant qu'il est

«nécessairement lié au prestige dont jouit une langue ou le peuple qui la parle (mélioration), ou bien au mépris dans lequel on tient l'un ou l'autre (péjoration)» (2012:117).

14 S'agissant des contes populaires, nous pensons que c'est le genre lui-même qui a d'abord été longtemps méprisé avant de gagner en estime, d'abord par l'action des folkloristes, puis à la faveur des études interculturelles. Désormais, on pourrait plutôt parler de l'hospitalité de la langue française accordée aux langues-sources des contes.

\section{- Emprunts lexicaux}

Les emprunts lexicaux permettent un accès sur certaines caractéristiques (genre, nombre, articles, etc.) de la langue source.

(15) [5] ...jfoûn de couscous

(16) $[5]$... chaque jefna vide

(17) [5] ...un ogre ... l'awarzeniou .

(18) [5] un grand debbouz de fer... massue...

(19) [7] Elle mit pourtant la tasilt sur le feu...

16 Les exemples «jefna " et "jfoun» informent sur le genre et le nombre du mot emprunté à l'arabe algérien; "L'awarzeniou » et "la tasilt», sur la formation du masculin et du féminin en tamazight de Kabylie. "Debbouz ", mot présent aussi en tamazight, est ici utilisé dans sa forme arabe dialectale. Les emprunts lexicaux peuvent se retrouver en grand nombre dans un même conte publié par un auteur.

\section{- Pérégrinismes}

Dubois et Al. Ecrivent :

« Le pérégrinisme renvoie encore à la réalité étrangère, mais la connaissance de son sens est supposée partagée par l'interlocuteur » (2012)

(20) [6] la thadjemâth 
(21) [7] l'aguellid

(22) [4] un yatagan

Le pérégrinisme semble s'imposer par une dénotation très forte en langue source, objet d'un intérêt particulier accordé par les locuteurs de la langue d'accueil. Il peut être relatif à une pratique inédite (thadjemâth), à une époque charnière de l'histoire transnationale (aguellid) ou d'un objet distinctif propre à une aire géographique ou à une époque historique mais dont l'effet la déborde (yatagan). Comme les contes, ils traversent le temps et l'espace, suggérant des récits qui les accompagnent implicitement.

Qu'ils soient communs à divers discours sociaux francophones ou que leur usage soit restreint au domaine du patrimoine immatériel comme nous le verrons plus bas, les pérégrinismes éclairent davantage le processus au bout duquel les mots sont intégrés dans une langue.

\section{- Emprunts lexicaux intégrés}

19 Certains emprunts lexicaux sont des termes intégrés à la langue française. Ils se rapportent à divers domaines.

(23) [10] un chikh le trouva sur la banquette du roi.

(24) [16] menhir

(25) [3] couscous

(26) [7] au soûq

(27) [10] l'oued.

(28) $[10]$ franc

(29) [6] le marabout de la ville

Ils peuvent référer à des faits religieux, sacrés ou mystérieux (chikh, menhir) comme à divers faits de la vie profane, qui n'ont pas tous cours de nos jours (couscous, soûq, oued).

Il n'est en outre pas impossible de rencontrer dans les contes certains termes qui ont d'abord été empruntés à une autre langue par la langue source dans laquelle ils peuvent avoir été désémantisés et être devenus archaïques, et revenir par le biais du conte à la littérature francophone dans laquelle ils sont susceptibles d'avoir un sens très actuel. C'est ici le cas du mot «franc », ainsi que du nom « marabout » que nous reverrons plus loin.

\section{- Emprunts sémantiques}

L'emprunt sémantique est défini par Cheriguen comme étant

« une unité de fonctionnement d'une ou plusieurs parties susceptibles d'un usage syntaxique autonome. Il est mis en morphologie, car formé dans la langue-cible même (différence avec l'emprunt lexical), mais seulement par imitation. D'où son rapport avec la langue source » $(1988$, p. 56).

Dans les contes, ils sont assez difficiles à repérer, à moins de penser en langue-source au moment de lire le texte francophone.

(30) [13] c'était un petit chien qui gardait la porte...

(31) [10] - Sans faute, sans faute, quand le perroquet pondra, envoie les enfants porter l'œuf au juif. 
L'expression " petit chien » peut signifier un chien, âgé, de petite taille. Mais elle semble être obtenue en calquant l'expression usitée (à l'oral) en tamazight de Kabylie « aqjih amecțuh » (petit chiot).

La répétition "sans faute, sans faute " (31) est peut-être due à une traductionadaptation machinale de l'expression « xlaṣ-xlaṣ » qui signifie justement «sans faute », tandis que «xlaș» peut signifier «fini » ou "pas du tout». De ce fait, cet exemple semble être un calque, alors qu'il s'agit plus proprement d'un emprunt sémantique : il est nécessaire qu'il soit composé (de deux lexies identiques en tamazight), mais la répétition en français reprend le ton sans être indispensable du point de vue sémantique.

\section{c. Calques}

Pour définir le calque, Cheriguen écrit qu'il est :

«mis en morphologie, issu de la langue-même au plan du signifiant (base appartenant à la langue). Mais sa formation nécessite le recours à une languesource. La différence avec l'emprunt sémantique, c'est que le calque est toujours un composé » $(1988$, p. 56)

(32) [10] j'ai fait mes recommandations (à ma femme)...

(33) [1] Ma mère ! ma mère !...

(34) [9] on servit du couscouss avec ce bœuf.

(35) [4] Et cette voix était celle du septième Notable.

(36) [7] Il y avait et il y avait - lys et basilic, herbes du Prophète, sur lui la prière et le salut - et il y avait une vieille...

Dans ce contexte (32), le verbe "weș̦̣i » en tamazight se comprend à lui seul comme "faire ses recommandations aux gens de la maison ou à l'épouse». La mise entre parenthèses du complément «à ma femme » met en valeur la présence d'un emprunt sémantique que l'incise vient éclairer au besoin.

Ce qui peut sembler n'être qu'un appel répété à la maman (33) du personnage est en fait une interjection («A yemm'A yemma!») exprimant la crainte panique en tamazight de Kabylie.

L'expression "couscous avec ce bœuf» (34) ancre entièrement ce repas dans le cadre diégétique et le coupe des traditions culinaires populaires nord-africaines et de la contance orale dans laquelle on parlerait plus volontiers de "seksu d weksum" (couscous à la viande), l'une des nombreuses variétés de couscous.

L'expression "septième notable» (35) n'exprime pas seulement une distinction ordinale, elle suggère en situation de contance orale de Kabylie d'être rattachée au dicton "sebea medden, yiwen d lyut» (de sept personnes -réunies-, l'une est un sauveur), ce qui est amplement souligné par la prise de position du personnage dans cette séquence de conte.

Le procédé du calque peut toucher les locutions figées. Ainsi, la formule d'ouverture de conte (36) en compte deux, une propre à l'ouverture des contes, y compris dans les mille et une nuits : « kan ya ma-kan » ou « kan ya makan », traduite par « il y avait et il $\mathrm{y}$ avait ». La seconde est une prière dédiée au prophète de l'islam: "3li-h sslat $\mathrm{w}$ sslam », traduite par « sur lui la prière et le salut ». 


\section{d. Noms propres et onomastique}

Abbas-Kara et Kebbas écrivent :

« Les calques visent ainsi à brouiller, à parasiter l'intercompréhension pour qui ne possède pas le même arrière-plan culturel » (2013).

(37) [2] Le « Génie de la mer »

(38) [4] « roi des Impies »

(39) [3] « le chêne de l'ogre »

(40) [3] « mon père Inoubba »

$\mathrm{Au}$ niveau des noms propres, il semblerait que cette propriété s'efface quelque peu lorsqu'ils sont traduits par des noms communs (38) et (39). Lieux de mémoire du récit en langue source et en contexte de contance, ils risquent de sembler anodins aux yeux du lecteur francophone. Ce caractère de nom propre peut être rendu par la majuscule comme dans (37). Mais la majuscule peut aussi induire en erreur et créer un nom propre là où il n'en est pas question dans les versions d'origine, comme dans $(40)^{2}$.

31 Les mêmes auteures précisent : «Les calques sont parfois accompagnés d'énoncés de la langue source dont ils représentent la traduction littérale ».

(41) [5] - A Zouina, ia bintî. A Zouina, ia bintî... O Zouina, ô ma fille...

(42) [10] Il trouva des figues hors de saison.

Ces traductions latérales peuvent se retrouver dans le corps même du texte (41), sous forme d'incises, ou dans le péritexte sous forme de notes de bas de page comme « Lexrif mebla lweqt » dans (42).

\subsection{Alternance et mélange de langues}

L'étude des contacts de langues dans les contes du point de vue de l'alternance codique et du mélange de codes linguistiques est intéressante dans la mesure où ces procédés d'écriture renseignent sur la distance mise entre le narrateur et les personnages, entre les instances diégétiques et la langue et le folklore à la source des contes, etc. Selon les auteurs et les contes, toutes ces dispositions se rencontrent: elles ne peuvent être traitées dans le cadre de cette étude. Nous nous limiterons à montrer par ces exemples la variété de leur prise en compte textuelle.

(43) [15] Le soir venu, la mère voulut traitre la vache. « Tourne-teu, Noirotte. -Nenni, je n'me tournerâme. "

(44) [15] « Te vlà not' Poucet ! j'te croyeuille pordeu...

(45) [19] «T'en faiou et t'en refaiou ", dit-elle à cette enfant ; « il faut que tu me fasses rire autant que tu m'as fait pleurer. »

(46) [19] Tout le monde criait : « A terracamina !»

Qu'il s'agisse de dialogues (43), (44), de formulettes (45) ou d'exclamations (46), en français dialectal ou en une autre langue, il arrive que l'alternance codique soit donnée à déchiffrer par le lecteur en s'aidant du contexte intratextuel.

(47) [17] Et voilà que les meules se mirent à parler. Au rythme du tic-tac du moulin, elles disaient : - Sat bol fé ja pot ! Sat bol fé ja pot! (Si elle veut, elle peut ! Si elle veut, elle peut!)

(48) [17] Et l'assistance muette de saisissement entendit, mêlées au tic-tac du moulin, ces paroles bien-pensantes: - Diu nous adjudara! Diu nous adjudara! (Dieu nous aidera! Dieu nous aidera !)

Multilinguales, 12 | 2020 
(49) [17] - Sé nat bol fé qu'at deïtché ! Sé nat bol fé qu'at deïtché ! (Si elle ne veut pas qu'elle le laisse ! Si elle ne veut pas qu'elle le laisse !)

Il arrive néanmoins que les propositions hétérolectes soient accompagnées d'explications mises entre parenthèses comme c'est le cas dans les exemples (47), (48) et (49)

(50) [10] Mon histoire a suivi son cours comme l'oued. Je l'ai racontée à de nobles gens.

(51) [10] II ramassa cet argent : chaque cœur qui tombait, il le ramassait.

(52) [10] - As-tu des enfants par hasard ? Tu n'en as pas! je ne te connais pas et tu ne me connais pas! » - Viens en justice »

(53) [6] - Qu'as-tu donc, lui demanda sa femme, ô toi que le destin m'a donné ? »

Le contact de langue mêlant l'alternance codique (50) et le calque (52) peut aussi apparaitre, aussi bien dans les propos du narrateur (51) que des personnages (53).

\subsection{Faits de bilinguisme ou d'universalisme culturel}

\section{a. Adaptation de motifs}

L'une des caractéristiques les plus admises des contes populaires est qu'ils peuvent se rencontrer de manière plus ou moins similaire dans plus d'une région ou culture. Ainsi que le montrent Charnay et Charnay (2014), leurs motifs -et selon nous, certains personnages mythiques- sont assez souvent réadaptés aux valeurs et croyances locales de chaque version. Plusieurs folkloristes ont par ailleurs signalé la présence de motifs identiques dans des contes différents, parfois recueillis dans des régions éloignées. Exemples :

(54) [4] « Parle, bougie, et raconte l'histoire des frères qui vivaient... Parle, bougie, ou je parlerai : Souviens-toi, ils étaient trois... »

(55) [4] Puis elle pétrit sa galette et la mit à cuire dans le plat qu'à dessein elle avait posé à l'envers sur le feu.

(56) [19] Et elle se met des morceaux de toutes les choses qu'on mangeait dans la poche. Les deux autres la voient. Le bal commence et pendant qu'elle dansait, il lui sortait de la poche toutes sortes de belles choses, des oiseaux d'or et des diamants.

Ainsi, le passage (53) rappelle un autre dans l'épisode de la fée-arbrisseau dans le conte Soumicha; le Stratagème (55) se rencontre dans plusieurs autres contes, dont celui de $\hat{O}$ Vou-Idhmim mon fils! et Zalgoum (Taos Amrouche). Le motif de choses mises dans la poche (56) se retrouve dans La princesse d'Angleterre sous une autre forme.

Outre ces adaptations d'ordre culturel, il nous semble pertinent d'évoquer la mise en texte par les différends auteurs et de se demander s'il y a lieu de parler d'adaptations auctoriales aux contextes textuels respectifs des contes dans lesquels ils figurent. La question se pose d'autant plus que l'on peut trouver les mêmes contes, recueillis dans les mêmes terroirs, par des auteurs différents.

\section{b. Lexique folklorique et culturel universel}

37 Certains éléments folkloriques sont présents dans des contes de diverses cultures. Ils constituent ainsi des realea historiques et folkloriques universels. Ceci dit, les représentations respectives peuvent largement différer d'une culture à l'autre.

(57) [18] sorcier

(58) [5] château de l'ogre 
(59) [4] les serviteurs arrivèrent avec leur gibecière pleine

(60) [18] Une fée, une princesse, un roi

(61) [14] Perruquier, décrotter les souliers, vendeur de faïence

C'est ce qui permet de se suffire d'une désignation indéfinie comme dans les exemples

(57) et (60) ou d'une image stéréotypée (59), parfois composée (58). Globalement, les noms de métiers, tels qu'ils figurent dans [61] le sont aussi ${ }^{3}$.

\subsection{Interférences et approximations culturelles et linguistiques}

\section{a. Interférences et inadéquations lexico-sémantiques}

Plus aisée à détecter lorsque la langue et la culture source du conte sont connues, les insuffisances translinguistiques et transculturelles sont nécessairement une donnée assez constante de la publication de contes de terroirs de diverses parties du monde en français. Si les difficultés de la traduction peuvent en justifier certaines, il ne demeure pas moins plausible qu'elles puissent avoir pour origine la simple hésitation entrainant un choix, l'inattention ou l'insuffisante connaissance du folklore et/ou de la contance orale à la source du conte

(62) [8] pierre d'espérance

(63) [10] « Voici l'argent si tu ne crois pas. »

(64) [6] le marabout de la ville dont ... monta à la mosquée pour chanter la prière ...

(65) [7] le fils du roi (aguellid)

(66) [10] - On lui dit : « 0 Medrabalef, tiens-toi à la fenêtre, je te donne « alef » (mille)». Dès qu'on lui donne mille francs, elle arrive. "

Ainsi, l'expression "pierre d'espérance» (62) est une traduction approximative de « Hedjret ssber » en arabe algérien, à la traduction de laquelle l'expression «pierre de patience » aurait été plus ajustée ${ }^{4}$.

L'expression «si tu ne crois pas » (63) est syntaxiquement tronquée et sémantiquement ambigüe de telle sorte que la réception du discours du personnage peut induire en erreur : laisser inférer que l'argent n'est donné que si l'interlocuteur est un incroyant alors qu'il est montré pour convaincre de la bonne foi du locuteur.

Le nom «marabout» (64) est un mot français d'origine étrangère. En Algérie, " marabout » n'est pas synonyme de «cheikh", encore moins d' "imam», sens qu'il prend en langue française. Son usage dans ce sens par une auteure algérienne en fait un contre-emprunt.

Dans (65), l'incise (aguellid) est accolée à l'expression « fils du roi » dont elle forme une explication tronquée: le "fils du roi » est un "prince» en langue française et « aguellid » est un « roi » en tamazight. Explique-t-il le roi ou le fils du roi ?

Pour parer à l'ambiguïté consécutive à la traduction d'un énoncé confus, les auteurs peuvent insérer des mots qui dans la version-source, n'existent pas forcément. Ainsi, dans (66), seule une adaptation à ce qui est connu de l'auteur/narrateur peut expliquer l'ajout du mot «francs » à l'adjectif «mille », pourtant suffisant dans le contexte du conte de Medrabalef.

\section{b. Interférences culturelles et historiques}

Certains mots ou expressions propulsent le conte hors du cadre spacio-temporel, généralement indéfini, des contes, autorisant des inférences rapprochant le conte de 
l'espace-temps présent. . Certains contes recueillis en France se rapprochent davantage des légendes, ce qui pourrait faire passer de tels éléments inaperçus. Mais, à la réception, ils peuvent, selon les traditions, se révéler comme autant d'entorses au genre.

(67) [7] l'aguellid fit donner à la vieille un livret pour quelle vînt toucher chaque mois une pension.

(68) [8] UN homme avait une fille qu'il envoyait à l'école ; l'enfant étudiait jusqu'au soir

(69) [10] - Il est vrai qu'il y a ici une noce, dans notre village : va manger là-bas ! » - Eh bien, grand-mère, donne-moi un récipient, j'apporterai la nourriture ici, nous mangerons ensemble. » Elle lui donna un récipient, il le remplit, l'apporta à la maison, ils mangèrent.

Dans l'exemple (67) le "livret de pension mensuelle», une création des sociétés contemporaines, est un élément baroque dans les contes des temps anciens. Dans (68), " école coranique " aurait été mieux indiquée si l'on se réfère à des sociétés rurales nord-africaines.

Dans (69), il revient aux gens de la noce d'offrir «tadellact $n$ tunțict », pas au convive d'en prendre de lui-même ; celui-ci peut évidemment ramener ce qu'il peut de la part qu'on lui sert en propre sans s'en référer à personne. Il s'agit donc d'une interférence culturelle, pouvant à la réception déformer la représentation que l'on peut se faire $\mathrm{du}$ personnage, voire de la culture de référence du conte.

41 L'expression "monta à la mosquée » dans l'exemple (64), usuelle en tamazight de Kabylie, évoque plus aisément l'emplacement au centre et au plus haut point d'un village du tell ou d'un ksar saharien d'Afrique du nord que le fait de "monter au minaret». La réception du rythme du récit peut ici se ressentir de l'ambiguïté de l'expression. L'ambiguïté touche également à l'expression «chanter la prière » dansle même exemple (64) car dans la pratique, l'appel rituel à la prière peut, suivant les imams, être mélodieux, sans être un chant proprement dit. A la réception, l'expression $\mathrm{du}$ narrateur peut, suivant le lecteur, exolingue ou endolingue, installer l'incompréhension ou déclencher une réaction ironique.

\section{c. Désignations par défaut}

$42 \mathrm{Si}$, dans l'écriture romanesque, l'enjeu de la dénomination des choses est important, il arrive que dans les contes de terroirs populaires l'on évite le xénisme et l'emprunt pour se limiter à la désignation minimale d'un objet inconnu de la langue française.

(70) [16] [19] plat en terre

Il est certain que " plat en terre » de l'exemple (70) et « récipient » dans l'exemple (69) désignent des objets ayant des noms appropriés dans les langues concernées.

\subsection{Contacts de phraséologies}

Le genre du conte étudié se distingue par certaines catégories de locutions figées : une locution peut constituer un nom propre de personnage ou d'un endroit, une formule d'entrée ou de sortie du conte, une formulette magique ou rituelle, ou une réplique mémorable d'un personnage usitée dans l'un des univers constitutifs du conte. Elles participent de son caractère folklorique. Elles sont assez reconnaissables à leur emplacement et à leurs effets sur les personnages qui les énoncent ou auxquels elles 
s'adressent. Suivant les auteurs et les contes, elles sont prises en compte, empruntées et/ou non expliquées, traduites ou calquées, ou non.

A celles-ci, s'ajoutent des éléments de la phraséologie courante de la langue ou variante source et/ou française. On ne peut s'en faire une idée contrastive que dans la mesure où la langue source du conte concernée est connue.

Le conte populaire publié en français en tant que genre littéraire est un terrain de rencontre scripturale entre le français d'une part, et respectivement les différentes langues-sources des contes. C'est aussi, au pôle de la réception, un espace littéraire dans lequel le lecteur va à la rencontre d'une grande variété de langues, précisément de mots et d'expressions référant aux codes linguistiques, aux pratiques anthropologiques et aux univers folkloriques imaginaires les plus divers. Au fur et à mesure qu'il y rencontre des éléments et des aspects relevant de son patrimoine linguistique et culturel propre, le lecteur évalue la façon dont ils sont insérés dans la composition du conte, confronte ce qui y est inséré à ses propres connaissances de son patrimoine propre, puis part à la découverte de ce qui caractérise d'autres patrimoines et de ce que les uns et les autres ont ou peuvent avoir en commun.

Les contes se définissent davantage par l'origine géolinguistique et culturelle de leur recueil et par les univers folkloriques qui les distinguent des autres formes de récit, à la différence des romans qui se classent par écoles, tendances et époques auctoriales. De plus, les procédés d'écriture et les enjeux liés à la découverte et à la sauvegarde des contes sont nettement différents des autres genres de récit tel que le storytelling ou le roman. Il nous semble que ce sont là deux premières raisons qui font que les contacts de langue dans le genre du conte populaire publié en français peuvent constituer une entrée très féconde dans l'enseignement/ apprentissage de ce genre littéraire.

Appuyée sur ce qui pourrait être une sociolinguistique de la réception littéraire, l'enseignement/apprentissage de ce genre peut favoriser l'évolution de l'apprenant allant du bilinguisme au plurilinguisme et des contacts des cultures à l'intelligence interculturelle, des savoirs linguistiques, y compris oraux, à leur usage dans le genre du discours, de la lecture «loisir » à la lecture critique permanente, voire à l'écriture littéraire performante.

\section{Contes sources des exemples cites}

Taos Amrouche. Le Grain magique. Paris : La Découverte, 1996 :

[1] « La mare où éteindre ces flammes o aicha ma fille !»;

[2] « La princesse Soumicha »;

[3] « Le chêne de l'ogre »;

[4] « Roundja, la jeune fille plus belle que lune et que rose ».

Emile Dermenghem. Contes kabyles. Éditions Charlot, Alger, 1945 :

[5] «Le garçon qui triompha de l'ogre».

J. Riviere. Contes populaires : La Kabylie du Djurdjura. Paris : Ernest Leroux, 1882 :

[6] « Le roi et son fils»;

[7] « La vieille, les deux orphelins et le fils du roi »;

[8] « L'ange et l'orpheline».

René Basset. Contes populaires d'Afrique. Paris : E. Guilmoto, 1903 :

[9] « Hamed Ben Çeggad».

Le Fichier Périodique berbère. Contes merveilleux et fables. ayamun.com, Juin 2015 :

[10] « Conte de Medrabalef ».

Jean Markale. Contes populaires de toutes les Bretagne. Éditions Ouest-France, 2004 : 
[11] « Le merle au bec d'or »;

[16] « Le trésor des korrigans ».

Emmanuel Cosquin. Contes populaires de Lorraine. Paris : F. Vieweg :

[12] « Léopold»;

[13] « La pantoufle de la princesse »;

[14] « La princesse d'Angleterre »;

[15] « Le petit poucet».

Jacqueline Mirande. Contes et légendes du Pays d'Oc. Paris : Nathan :

[17] « Les moulins qui parlent »;

[18] « Les trois cils ».

James Bruyn Andrews (1892). Contes ligures : traditions de la Rivière. Paris : Ernest Leroux, $1892:$.

\section{BIBLIOGRAPHIE}

[19] « Terra-Camina ».

ABBES-KARA, Attika-Yasmine, KEBBAS, Malika, « Pour une problématisation des 'écritures bilingues' dans la littérature francophone algérienne », SOCLES n² 2, Alger, 2013, p. 21-36. Disponible sur <https://www.asjp.cerist.dz/en/article/2636>

AMMOUDEN, M'hand, HAMADACHE, Tahar, « Les mondes (im) possibles du conte au service de la communication interculturelle », Revue de philologie et de communication interculturelle vol. II $\mathrm{n}^{\circ} 1$ (3), Roumanie, 2018, p. 113-124. Disponible sur <http://www.llcs.journal.mta.ro/wp-content/ uploads/2018/02/Mondes-_Im_possibles_ED.pdf> (consulté le 8 mars 2018)

BOUTET, Josiane, MAINGUENEAU, Dominique, « Sociolinguistique et analyse de discours : façons de dire, façons de faire », Langage et société, 2005/4 n 114, p. 15-47. Disponible sur < https:// www.cairn.info/revue-langage-et-societe-2005-4-page-15.htm>

CHARNAY, Bochra, CHARNAY, Thierry, « Le conte facteur d'interculturalite », Multilinguales $\mathrm{N}^{\circ}$ 3, université de Bejaia, 2014. Disponible sur <https://www.asjp.cerist.dz/en/article/1547>

CHERIGUEN, Foudil, «Typologie des procédés de formation du lexique », Cahiers de lexicologie, no 55 . Paris, Didier, 1989.

CHERIGUEN, Foudil, « Les mots des uns, les mots des autres : Le français au contact de l'arabe et du berbère ", Alger : Casbah Editions, 2002.

CLEMENT, Murielle Lucie, « Poétique du multilinguisme chez Andreï Makine », dans GASQUET AXEL et SUAREZ MODESTA (Dirs.), « Écrivains multilingues et écritures métisses. L'hospitalité des langues », Clermont-Ferrand : Presses Universitaires Blaise Pascal, 2007, pp. 165-180.

DUBOIS Jean et Al., « Le dictionnaire de linguistique et des sciences du langage », Paris : Larousse, 2012.

HAMADACHE, Tahar, « Oralité et littérature dans le genre conte : approche discursive et sociodidactique », dans Action Didactique $n^{\circ}$ 1, Université de Bejaia, 2018, Pp. 1-15. Disponible sur <http://univ-bejaia.dz/action-didactique/AD1/T.Hamadache> 
HAMADACHE, Tahar, AMMOUDEN, M'Hand, « Traces de l'oral dans les contes écrits et intérêts didactiques », dans Socles n 12, Alger : LISODIP, 2018. Disponible sur <https:// www.asjp.cerist.dz/en/article/104991>

HAMADACHE, Tahar, AMMOUDEN, M'hand, « Les traces de la langue-culture d'origine dans les traductions du conte La Vache des orphelins », dans Synergie Turquie n 12 (à paraitre), 2019.

KOSSOGOROVA, Christina, « Aspects sociolinguistiques et valeur culturelle des contes russes ", dans : «Revue du Centre Européen d'Etudes Slaves - Représentations artistiques, poétiques et littéraires slaves » $\mathrm{N}^{\circ}$ 1. Disponible sur <http://etudesslaves.edel.univ-poitiers.fr/index.php? $\mathrm{id}=276>$

MEIZOZ, Jérôme, (2005). « La « langue peuple » dans le roman français », HERMES 42, 2005, p. 101-106.. disponible sur <http://documents.irevues.inist.fr/bitstream/handle/2042/8989/ HERMES_2005_42_101.pdf> (Consulté le 22.07.2016)

\section{NOTES}

1. Le numéro de l'exemple est mis entre parenthèse tandis-que le numéro mis entre crochets renvoie au conte duquel il est pris.

2. En tamazight de Kabylie, cette expression, prononcée «vava-ynu v'va » est une juxtaposition de deux façons affectives de dire «vava " (père) : il s'agit de "vava-ynu » (mon père à moi) et «v'va », contracté comme dans «p'pa ». Elle fait partie d'une formule ou mot de passe entendu entre les personnages, «ttxil-ek ldi-yi-n tagurt, a vava-ynu v'va » (Je te prie de m'ouvrir la porte vers toi, ô mon père à moi, p'pa).

3. Certains noms de métiers se rattachent à des cultures particulières. Ainsi, un perruquier est sans doute caractéristique de certaines cultures (européennes occidentales) et pas d'autres.

4. En tamazight de Kabylie, "tabladt » (pierre plate) qui peut signifier pierre tombale, ou le renoncement à quelque chose dans l'expression «err-as tabladt i wul» (se mettre une pierre plate sur le cœur), elle fait partie d'un procédé de résistance à la faim utilisé lors de travaux durs par temps de disette. Ce procédé, rendu par la locution «bges tablaḍt » (se ceindre d'une petite pierre plate) qui contient l'idée de patience et de résistance, consiste à s'appliquer ce type de pierre sur l'ombilic et se ceindre fortement.

\section{RÉSUMÉS}

Les contes populaires publiés en français offrent un terrain particulier de contacts de langues. Ceux étudiés ici constituent un bilinguisme de contes proche de celui littéraire, tout en s'en distinguant des points de vue de l'énonciation, de la composition discursive, des référents socioculturels et folkloriques, etc. Les enjeux de ces contacts, ici liés à la réception, sont sociodidactiques.

Popular tales published in French provide a particular ground for language contacts. Those studied here constitute a bilingualism of tales close to the literary one, while distinguishing themselves from the points of view of enunciation, discursive composition, socio-cultural and 
folkloric references, etc. The stakes of these contacts, here related to the reception, are sociodidactic.

INDEX

Keywords : language contacts, literary bilingualism, francophone folktales, genres of speech, sociodidactic

Mots-clés : contacts de langues, bilinguisme littéraire, contes francophones, genres de discours, sociodidactique

\section{AUTEUR}

\section{TAHAR HAMADACHE}

Laboratoire LAILEMM, Faculté des lettres et des langues, Université de Bejaia, 06000 Bejaia, Algérie. 